\title{
Hybridization, transgressive segregation and evolution of new genetic systems in Drosophila
}

\author{
H. A. RANGANATH* and S. ARUNA \\ Drosophila Stock Centre, Department of Studies in Zoology, University of Mysore, \\ Manasagangotri, Mysore 570 006, India
}

\begin{abstract}
Introgressive hybridization facilitates incorporation of genes from one species into the gene pool of another. Studies on long-term effects of introgressive hybridization in animal systems are sparse. Drosophila nasuta $(2 n=8)$ and D. albomicans $(2 n=6)$ - a pair of allopatric, morphologically almost identical, cross-fertile members of the nasuta subgroup of the immigrans species group - constitute an excellent system to analyse the impact of hybridization followed by transgressive segregation of parental characters in the hybrid progeny. Hybrid populations of D. nasuta and D. albomicans maintained for over 500 generations in the laboratory constitute new recombinant hybrid genomes, here termed cytoraces. The impact of hybridization, followed by introgression and transgressive segregation, on chromosomal constitution and karyotypes, some fitness parameters, isozymes, components of mating behaviour and mating preference reveals a complex pattern of interracial divergence among parental species and cytoraces. This assemblage of characters in different combinations in a laboratory hybrid zone allows us to study the emergence of new genetic systems. Here, we summarize results from our ongoing studies comparing these hybrid cytoraces with the parental species, and discuss the implications of these findings for our understanding of the evolution of new genetic systems.
\end{abstract}

[Ranganath H. A. and Aruna S. 2003 Hybridization, transgressive segregation and evolution of new genetic systems in Drosphila. J. Genet. 82, 163-177]

\section{Introduction}

Hybridization is the crossing of individuals belonging to two unlike natural populations that have secondarily come in contact (Mayr 1963). There are contradictory views regarding the potential role of hybridization in evolution. In plants, hybridization is considered to be a widespread and potentially creative evolutionary force that is thought to have contributed to past diversification during environmental changes (Anderson 1949; Anderson and Stebbins 1954; Cruzan and Arnold 1993; Rieseberg et al. 1996; Fritz 1999). On the other hand, it has been thought that the evolutionary role of interspecific hybridization in ani-

*For correspondence. E-mail: drosrang@ sancharnet.in.

This paper is dedicated to the memory of our teacher, Prof. N. B. Krishnamurthy. mals is small because, even when fertile hybrids are produced, there is severe selection against the genetically imbalanced gametes resulting through introgression (Mayr 1963). Of late, however, this concept of hybridization as an evolutionary dead-end in animals is being challenged by reports of frequent hybridization between closely related species (Barton and Hewitt 1989; Avise 1994; Arnold 1997; Goodman et al. 1999; Bruke and Arnold 2001), although hybridization between species that have diverged considerably could result in embryonic or adult lethality (Bock 1984), or male sterility even if the hybrids are viable (Haldane 1922). In situations where hybrids can survive and reproduce, giving rise to at least some offspring of mixed ancestry, the region is recognized as a hybrid zone, and such regions are of considerable evolutionary interest (Barton and Hewitt 1989; Harrison 1990).

Keywords. Drosophila nasuta; Drosophila albomicans; hybridization; cytoraces; new genetic systems. 
Many evolutionary biologists have viewed the hybrid zone as an active site for evolutionary change, wherein selection against hybridization shapes the causes and consequences of genetic and ecological interaction between differentiated populations. The potential ways in which hybridization can promote the origin of new characteristics are transgressive segregation, establishment of new genetic background, and increased incidence of new mutations (Stebbins 1973; Rieseberg et al. 1999). To be successful, these hybrid progeny must become stabilized through the establishment of true-breeding intermediate gene combinations, or introgressed genomes. Such introgressed systems can lead to production of recombinant genotypes that have properties different from those of either parent and, thus, this process can be an important source of new variation leading to the establishment of new genetic systems or genomes (Anderson 1949). Natural selection would tend to favour hybrids that have formed coadapted gene complexes (Dobzhansky (1949, $1970 a, b)$ by overcoming genetic incompatibility and that are, consequently, more viable and fertile (Templeton 1981; Barton 2001). Thus, in contrast to mutation, which has a constant rate across a range of species, hybridization can provide a much faster mechanism for generation of genetic variations wherein favourably interacting gene complexes are determined by hybrid founder events followed by natural selection, leading to the establishment of a new evolutionary lineage with a novel genome.

A potential hybrid zone can provide insights into the mechanisms of speciation for it reveals the genetic differences that have accumulated during the early steps of speciation. Hybrid-zone studies can yield information about the possible state and degree of divergence between populations that may be 'on the way' to differentiating into races / species (Hewitt 1988). Many natural hybrid zones are available for study of the evolutionarily significant mechanisms of the creation of new genetic systems via introgressive hybridization. However, one major drawback of these natural hybrid zones is the lack of information about their time of origin. Moreover, it may take a considerable time for populations to differentiate into neoforms, even with fairly high levels of gene flow. Thus, many such studies have been confined to estimating the age of the hybrid zone from the extent of differentiation reported. There seems to be a need for a hybrid zone whose age is precisely known and in which the speciating mechanism is traced and reported right from its origin. Such a system would help validate the accuracy of estimates provided for natural hybrid zones. However, most experimental hybridization studies in the past, especially on animals, have been confined to a few generations. Thus, there is a need for long-term hybridization experiments wherein a hybrid zone could be created in the laboratory as a parallel system simulating natural hybrid zones. In this paper, we describe results from experimental studies of the pot- ential role of hybridization in the formation of new genetic systems and in speciation, using an artificial hybrid zone created in the laboratory and earlier described by Tanuja et al. (1998).

\section{Drosophila nasuta and $D$. albomicans: a goldmine for evolutionary cytogenetics}

Over 90 per cent (perhaps 98 per cent) of all speciating events are accompanied by karyotypic changes and, in a majority of these cases, structural chromosomal rearrangements have played the primary role in initiating divergence (White 1978). However, Carson (1982) is of the view that in most cases the fixation of particular karyotypes is likely to be merely an incidental accompaniment of small-population effects and forced selection for reorganization as the species is formed.

The basic karyotype of the genus Drosophila is believed to be $2 n=12$, with five pairs of acrocentric rods, and a pair of small dot chromosomes. During the evolution of different groups of Drosophila from this so-called primitive karyotype, centric fusions and inversions, as well as additions or deletions of heterochromatin, have played a major role in shaping the karyotypic phylogeny. Studies tracing the steps involved in karyotypic evolution in the immigrans species group of Drosophila, with particular emphasis on the nasuta subgroup, have shown involvement of centric fusions in transforming the acrocentricdominated ancestral karyotype into a metacentric form (Ranganath and Hägele 1981; Rao and Ranganath 1990), an example of karyotypic orthoselection (sensu White 1973). D. nasuta Lamb with $2 n=8$ diploid chromosomes appears to have evolved from the putative ancestral karyotype via two centric fusions among the ancestral rods leading to two metacentric chromosomes, followed by a pericentric inversion in one of them, forming a double-length acrocentric chromosome. Thus the karyotypic composition of D. nasuta is a pair of metacentrics (chromosome 2), one pair of double-length acrocentrics (chromosome 3), one pair of acrocentric sex chromosomes, and a pair of small dot chromosomes. A further centric fusion of the doublelength acrocentric with the sex chromosomes, leading to a reduction in chromosome number, appears to have been involved in the formation of the $D$. albomicans Duda karyotype with $2 n=6$. Thus in addition to a pair of metacentrics (chromosome 2), and a pair of long dot chromosomes, D. albomicans has another pair of metacentricsthe product of centric fusion $(\mathrm{X} \bullet 3, \mathrm{Y} \cdot 3$ chromosomes $)$, also termed neo-sex chromosomes, where one arm is homologous to the double-length acrocentric (chromosome 3) and the other arm to the sex chromosome of D. nasuta (figure 1) (Ranganath and Ramachandra 1994).

There are also differences in heterochromatin and satellite DNA contents of these two species. D. nasuta has $22 \%$ heterochromatic region in the genome, whereas $D$. albo- 
micans has $12 \%$. Further, nearly $80 \%$ of the long dot chromosome of D. albomicans is heterochromatic, compared to $50 \%$ heterochromatin in the small dot chromosome of D. nasuta. The quantum of heterochromatin in $\mathrm{X} \bullet 3$ chromosome of $D$. albomicans is less than the total heterochromatin content of chromosomes $\mathrm{X}$ and 3 together in D. nasuta. However, in terms of polytene banding, the euchromatic components of the two species are effectively cytologically identical (Ranganath and Hägele 1982; Hägele and Ranganath 1983). D. nasuta has one major AT-rich satellite region with a density of $1.663 \mathrm{~g} / \mathrm{cm}^{3}$, which constitutes $7-8 \%$ of the genome. D. albomicans, on the other hand, has three major AT-rich satellite regions with densities of $1.674,1.665$ and $1.661 \mathrm{~g} / \mathrm{cm}^{3}$, which together make up $28-30 \%$ of the total DNA. The in situ hybridization of satellite DNA regions of the two taxa has revealed that they have common satellite sequences. Thus, there appears to have been an amplification of satellite sequences in D. albomicans in both the dot and Y chromosomes, and a concomitant reduction in the satellite content of chromosomes 2 and X•3 (Ranganath et al. 1982).

Structural changes in chromosomes and, hence, the karyotype of species in a lineage illuminate the history and presumed phylogeny of the concerned group. Yet, it is difficult to generalize the impact of such changes on the

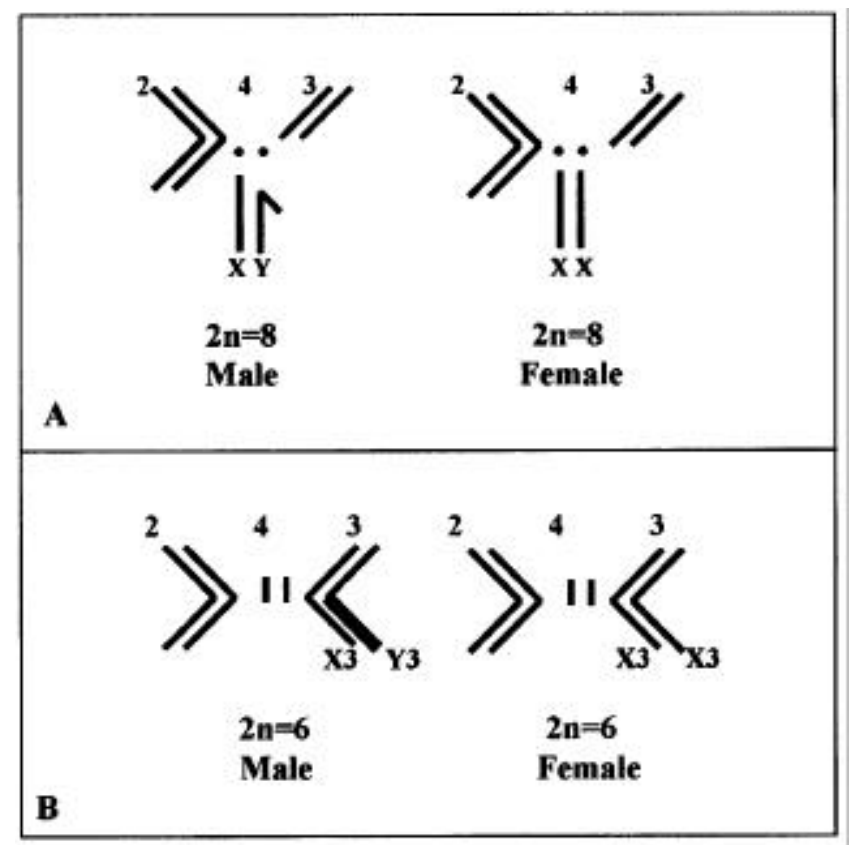

Figure 1. Karyotypes of D. nasuta (A) and D. albomicans (B). The centric fusion between autosomes 3 and sex chromosomes has resulted in the evolution of the karyotype of D. albomicans, with reduction in diploid number (Ranganath and Hägele 1981). Therefore Mahesh et al. (2000, 2001) have redescribed the karyotype of $D$. albomicans and have treated the autosome - sex chromosome fusion products, the $\mathrm{X} 3$ and $\mathrm{Y} 3$ chromosomes, as neo-sex chromosomes and the long dot chromosomes as chromosome 3. process of speciation. For example, even though D. mojavensis and $D$. arizonensis differ from one another by at least seven inversions, they can produce fertile hybrid offspring (Wasserman 1982). Similarly, D. virilis and D. americana texana, in spite of having different karyotypes owing to fusion between an autosome and the sex chromosomes, produce fertile hybrids (Throckmorton 1982). Likewise, significant karyotypic divergence involving centric fusions, major structural reorganization in dot chromosomes, changes in the pattern and distribution of heterochromatin, and amplification of satellite DNA sequences has occurred during the evolution of D. albomicans. Yet D. nasuta and D. albomicans are cross-fertile and hybrid progeny can be maintained for many generations, and hence it has been suggested that they be treated as chromosomal races (Nirmala and Krishnamurthy 1972; Ramachandra and Ranganath 1987; cf. Ranganath 2002). On the other hand, Wilson et al. (1969) have felt that since $D$. albomicans has a different karyotype from $D$. nasuta it should be treated as a distinct species in the nasuta subgroup. Kitagawa et al. (1982) prefer to treat D. nasuta and D. albomicans as semi-species of the nasuta complex, on the basis of sexual isolation and insemination test. Likewise, Chang and Ayala (1989) have opined that D. nasuta and D. albomicans fit the category of 'super species' of Mayr (1963). However, the biological species concept (Mayr 1963) requires reproductive isolation between species. Despite karyotypic divergence, since D. nasuta and $D$. albomicans enjoy mutual open genetic systems, they should, therefore, be treated as chromosomal races (Ranganath et al. 1974). On the other hand, according to the phylogenetic species concept, species are recognized strictly in terms of their status as diagnosable evolutionary taxa (Cracraft 1983). Following this concept, two sister taxa could broadly hybridize and still be considered as species if each is diagnosable as a discrete taxon. By the criterion of the phylogenetic species concept, therefore, D. nasuta and D. albomicans, which are karyotypically different and occupy two distinct positions in the karyotypic phylogenetic tree of the nasuta subgroup, have to be treated as species. The most important aspect of D. nasuta and $D$. albomicans to consider at this juncture is that hybridization between D. nasuta and D. albomicans is observed only in the laboratory, because these two species are allopatric in nature and, consequently, have no opportunity to hybridize, resulting in the protection of the distinct identities of their respective gene pools.

\section{Origin of the hybrid zone: the nasuta- albomicans complex}

Interracial hybridization between D. nasuta $(2 n=8)$ and $D$. albomicans $(2 n=6)$ leads to a hybrid gene pool. The chromosomes of $D$. nasuta and $D$. albomicans can be 
identified on the metaphase plate with certainty on the basis of the heterochromatin content of each chromosome in the two parents. The $\mathrm{F}_{1}$ hybrids have $2 n=7$, with four chromosomes of D. nasuta and three of D. albomicans. In $\mathrm{F}_{2}$ and subsequent generations, karyotypic mosaicism is noticed, with a variety of individual karyotypes, such as nasuta type, albomicans type, $\mathrm{F}_{1}$ type, and also new combinations (Ranganath 1978; Rajasekarasetty et al. 1979; Yu et al. 1997). To study the dynamics of chromosomal segregation during gametogenesis in the $F_{1}$ hybrids, and its impact on the fertility of the next generation, a systematic assessment was made by Ranganath and Krishnamurthy (1981). $F_{1}$ males produced six different types of sperm, of which $39 \%$ had normal haploid chromosome complement while the remaining $61 \%$ were aneuploids for the chromosomes $X$ and 3. On the other hand, the $F_{1}$ females produced only two types of eggs with the normal haploid complement of chromosomes, and aneuploid eggs were not observed. Fertility test on $\mathrm{F}_{2}$ and backcross progeny revealed males to be sterile more often than females. Out of 400 males and 400 females, 177 males and only 14 females were found to be sterile. Thus $\mathrm{F}_{1}$ luxuriance followed by $F_{2}$ breakdown was noticed for a few parameters of fitness, namely fecundity, rate of development and viability (Ranganath 1978). The $F_{2}$ breakdown was attributed to abnormal chromosomal segregation during the hybrid meiosis (Ranganath and Krishnamurthy 1981). Even then, the few fertile individuals that could survive and reproduce contributed to the next generation and, consequently, these hybrid populations could be maintained in the laboratory for a number of generations.

With this background, we initiated a series of longterm hybridization experiments to systematically assess the fate of chromosomes of D. nasuta and D. albomicans in hybrid populations over generations in a laboratory hybrid zone (figure 2). The $\mathrm{F}_{2}$ and later generations showed polymorphism with respect to chromosomal constitution. Each of these hybrid populations was independently cultured in a separate cage, often with population-size bottlenecks, especially during the early generations after hybridization. In some of the hybrid lineages, there was a gradual decline in the degree of karyotypic mosaicism, and karyotypically stabilized forms became established. These stabilized karyotypic neo-races were monomorphic for different novel combinations of parental chromosomes, and were termed cytoraces (Ramachandra and Ranganath 1985, 1988, 1990, 1996; Ranganath and Ramachandra 1987). Four such karyotypically stable hybrid cytoraces were obtained after the first round of hybridization, and their karyotypic compositions were as follows (The superscript on each chromosome indicates the parent from which it was inherited):

Cytorace 1: (males $2 n=7$, with $2^{\mathrm{n}} 2^{\mathrm{a}} 4^{\mathrm{n}} 4^{\mathrm{n}} 3^{\mathrm{n}} \mathrm{Y}^{\mathrm{n}} \mathrm{X} \cdot 3^{\mathrm{a}}$; females $2 n=6$, with $2^{\mathrm{n}} 2^{\mathrm{a}} 4^{\mathrm{n}} 4^{\mathrm{n}} \mathrm{X} \cdot 3^{\mathrm{a}} \mathrm{X} \cdot 3^{\mathrm{a}}$ )
Cytorace 2: (males $2 n=6$, with $2^{\mathrm{n}} 2^{\mathrm{a}} 4^{\mathrm{a}} 4^{\mathrm{a}} \mathrm{Y} \cdot 3^{\mathrm{a}} \mathrm{X} \cdot 3^{\mathrm{a}}$; females $2 n=6$, with $2^{\mathrm{n}} 2^{\mathrm{a}} 4^{\mathrm{a}} 4^{\mathrm{a}} \mathrm{X} \cdot 3^{\mathrm{a}} \mathrm{X} \cdot 3^{\mathrm{a}}$ )

Cytorace 3: (males $2 n=8$, with $2^{\mathrm{n}} 2^{\mathrm{a}} \quad 3^{\mathrm{n}} 3^{\mathrm{n}} 4^{\mathrm{a}} 4^{\mathrm{a}} \mathrm{Y}^{\mathrm{n}} \mathrm{X}^{\mathrm{n}}$; females $2 n=8$, with $2^{\mathrm{n}} 2^{\mathrm{a}} 3^{\mathrm{n}} 3^{\mathrm{n}} 4^{\mathrm{a}} 4^{\mathrm{a}} \mathrm{X}^{\mathrm{n}} \mathrm{X}^{\mathrm{n}}$ )

Cytorace 4: (males $2 n=7$, with $2^{\mathrm{n}} 2^{\mathrm{a}} 4^{\mathrm{a}} 4^{\mathrm{a}} 3^{\mathrm{n}} \mathrm{Y} \cdot 3^{\mathrm{a}} \mathrm{X}^{\mathrm{n}}$; females $2 n=8$ with $2^{\mathrm{n}} 2^{\mathrm{a}} 3^{\mathrm{n}} 3^{\mathrm{n}} 4^{\mathrm{a}} 4^{\mathrm{a}} \mathrm{X}^{\mathrm{n}} \mathrm{X}^{\mathrm{n}}$ ).

These cytoraces are maintained in separate cages and are, consequently, independent genetic and evolutionary entities. In nature, following the formation of such hybrid races, intercrossing with parents and other hybrid races could result in clines for genetic variation across the hybrid zone, as has been reported for D. americana and D. texana (Patterson and Stone 1952; Throckmorton 1982; McAllister 2002). Such transient clines are of considerable interest for studying chromosomal rearrangements following hybridization and possible introgression. With the intention of creating a laboratory system analogous to such transient hybrid-zone clines, we carried out a second round of interracial hybridization in our laboratory system by crossing the parental species $D$. nasuta and $D$. albomicans with the four newly evolved cytoraces in various combinations. In this manner, 28 new hybrid populations
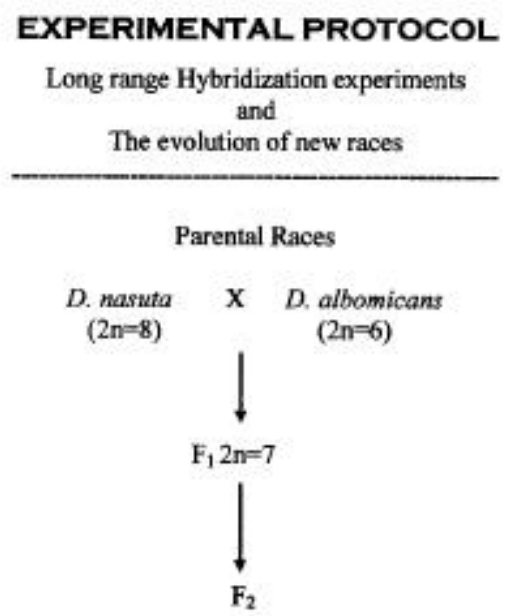

Karyotypic mosaicism
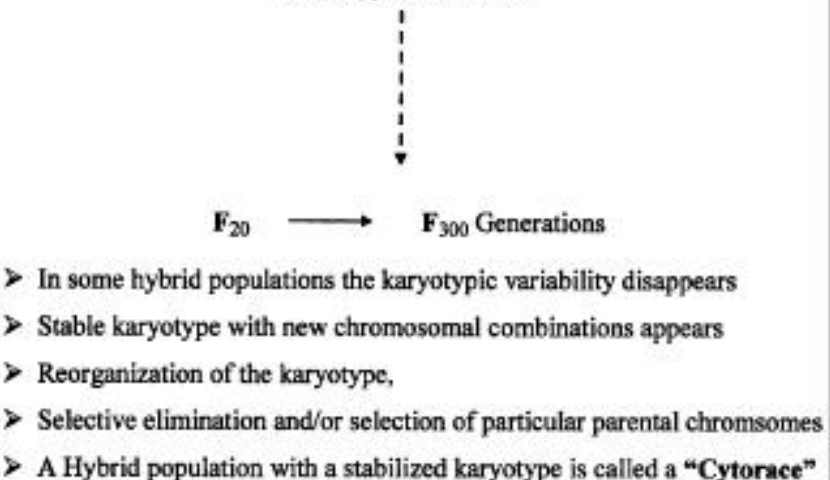

A Hybrid population with a stabilized karyotype is called a "Cytorace"

Figure 2. A schematic representation of the experimental setup of hybridization between $D$. nasuta and D. albomicans. 
were established. To speed up the differentiation of these polymorphic populations, we prevented gene flow among them, and their parents, by maintaining each population in a separate cage. These hybrid populations, consequently, experienced the genetic isolation characteristic of allopatry, while being reared under a common set of environmental conditions, a situation more similar to that experienced by sympatric populations, and have thus been referred to as being 'allo-sympatric' (Tanuja et al. 1998). Over a period of a few years, some of these populations resulting from the second round of hybridization also lost their karyotypic mosaicism, resulting in the laboratory evolution of a new set of 12 karyotypically monomorphic cytoraces (Ramachandra and Ranganath 1996; Tanuja et al. 1998; Tanuja 2000; Ranganath 2002).

The complete set of two parental species, the four initially established cytoraces, and the 12 cytoraces established after the second round of hybridization now constitute a laboratory hybrid zone. Since the entire gene pool of this hybrid zone is contributed by D. nasuta and D. albomicans, we have termed this hybrid zone with 18 races the nasuta-albomicans complex of the nasuta subgroup (Ramachandra and Ranganath 1996), whose members have been classified into eight categories on the basis of their diploid chromosomal complement (figure 3 ).

\section{Patterns of divergence in the nasuta- albomicans complex}

The members of the nasuta-albomicans complex have been studied in detail to uncover cytogenetic and other differences among them, and anagenetic changes leading to the establishment of different genetic systems have been documented. In this section, we summarize the more important results from this ongoing set of studies.

\section{Trends in the karyotypic evolution of cytoraces}

D. nasuta, D. albomicans and their hybrids have become a key system for understanding the implications and the impact of the hybridization in establishing new hybrid races through karyotypic repatterning. The chromosomes of the parental races, namely D. nasuta and D. albomicans, are differentially represented in the cytoraces.

The 'dot' chromosomes, in particular, present an interesting scenario. Each of the cytoraces is homozygous for either the nasuta dot (two cytoraces) or the albomicans dot (14 cytoraces) chromosomes. During the evolution of each cytorace, the initial $F_{1}$ was heterozygous for nasuta and albomicans dot chromosomes. During the subsequent hybrid generations, a transient phase of karyotypic instability was noticed, with three types of individuals, namely homozygous for nasuta dots, homozygous for albomicans dots, and heterozygous for these dots, in varying frequencies (Ramachandra and Ranganath 1985). The pro- longed inbreeding of such hybrid lineages has resulted in establishment of homozygous state for either dot chromosomes of nasuta or those of albomicans, but never a heterozygous state. There is reason to suspect that dot chromosome heterozygotes have lower fitness than the homozygotes owing to meiotic incompatibility between the dot chromosomes of D. nasuta and D. albomicans, which are very different. The metaphase dot chromosomes of D. albomicans are nearly five times larger than those of D. nasuta and contain a huge amount of heterochromatin. Polytene banding patterns of these chromosomes have also revealed that the dot chromosomes of $D$. albomicans are broader and shorter than those of D. nasuta. The large quantum of heterochromatin in the metaphase dot chromosomes of D. albomicans is found in the chromocentre, while in the euchromatic arm a few bands of the basal region are invertedly duplicated at the tip, resulting in a bending of the tip of the chromosome towards the base, making it broader as well as shorter. Moreover, in the polytene chromosomes of the $\mathrm{F}_{1}$ hybrids, the corresponding homologous chromosomes of nasuta and albomicans parents synapse completely whereas the arms of the nasuta and albomicans dot chromosomes exist as two independent entities without pairing (Hägele and Ranganath 1982). The most likely explanation for the observed homozygosity of dot chromosomes derived from D. nasuta or D. albomicans in hybrid cytoraces, therefore, is that of heterozygote disadvantage, with the relative fitness advantage of the two homozygotes varying among cytoraces based on differences in the genomic background. In cytoraces where the albomicans dot chromosome homozygotes are fitter than nasuta homozygotes, the albomicans homozygotes get fixed, and vice versa. Of course, a role for drift in the fixation of different dot chromosomes in different cytoraces also cannot be ruled out.

On the other hand, the metacentric chromosome 2 of D. nasuta and D. albomicans exists polymorphically in each of the cytoraces, with three types of individuals, namely homozygous for nasuta $\left(2^{\mathrm{n}} 2^{\mathrm{n}}\right)$, homozygous for albomicans $\left(2^{\mathrm{a}} 2^{\mathrm{a}}\right)$, and heterozygous $\left(2^{\mathrm{n}} 2^{\mathrm{a}}\right)$, suggesting either heterozygote advantage (Tanuja et al. 2003) or, perhaps, selective neutrality of $2^{\mathrm{n}}$ and $2^{\mathrm{a}}$. In either case, it suggests compatibility of these second chromosomes coming from the two different parents.

With regard to the sex chromosomes and autosome 3 components of the karyotype, the females of cytoraces can, in principle, have $\mathrm{X}^{\mathrm{n}} \mathrm{X}^{\mathrm{n}} 3^{\mathrm{n}} 3^{\mathrm{n}}\left(\right.$ nasuta) or $\mathrm{X} \cdot 3^{\mathrm{a}} \mathrm{X} \cdot 3^{\mathrm{a}}$ (albomicans) or $\mathrm{X}^{\mathrm{n}} 3^{\mathrm{n}} \mathrm{X} \cdot 3^{\mathrm{a}}\left(\mathrm{F}_{1}\right.$ type) chromosome complements. Similarly, the males of cytoraces may have either parental combinations such as $\mathrm{X}^{\mathrm{n}} \mathrm{Y}^{\mathrm{n}} 3^{\mathrm{n}} 3^{\mathrm{n}}$ (nasuta) or $\mathrm{X} \cdot 3^{\mathrm{a}} \mathrm{Y} \cdot 3^{\mathrm{a}}$ (albomicans) or the $\mathrm{F}_{1}$ type $\left(\mathrm{X}^{\mathrm{n}} \mathrm{Y}^{\mathrm{n}} \mathrm{X} \cdot 3^{\mathrm{a}}\right.$ or $3^{\mathrm{n}}$ $\left.\mathrm{X}^{\mathrm{n}} \mathrm{Y} \cdot 3^{\mathrm{a}}\right)$. In none of the cytoraces did females exhibit the $F_{1}$ karyotype $X^{n} 3^{n} X \cdot 3^{a}$. Females in seven cytoraces showed the nasuta type of arrangement of sex chromosomes and chromosome 3 , whereas nine cytoraces were 


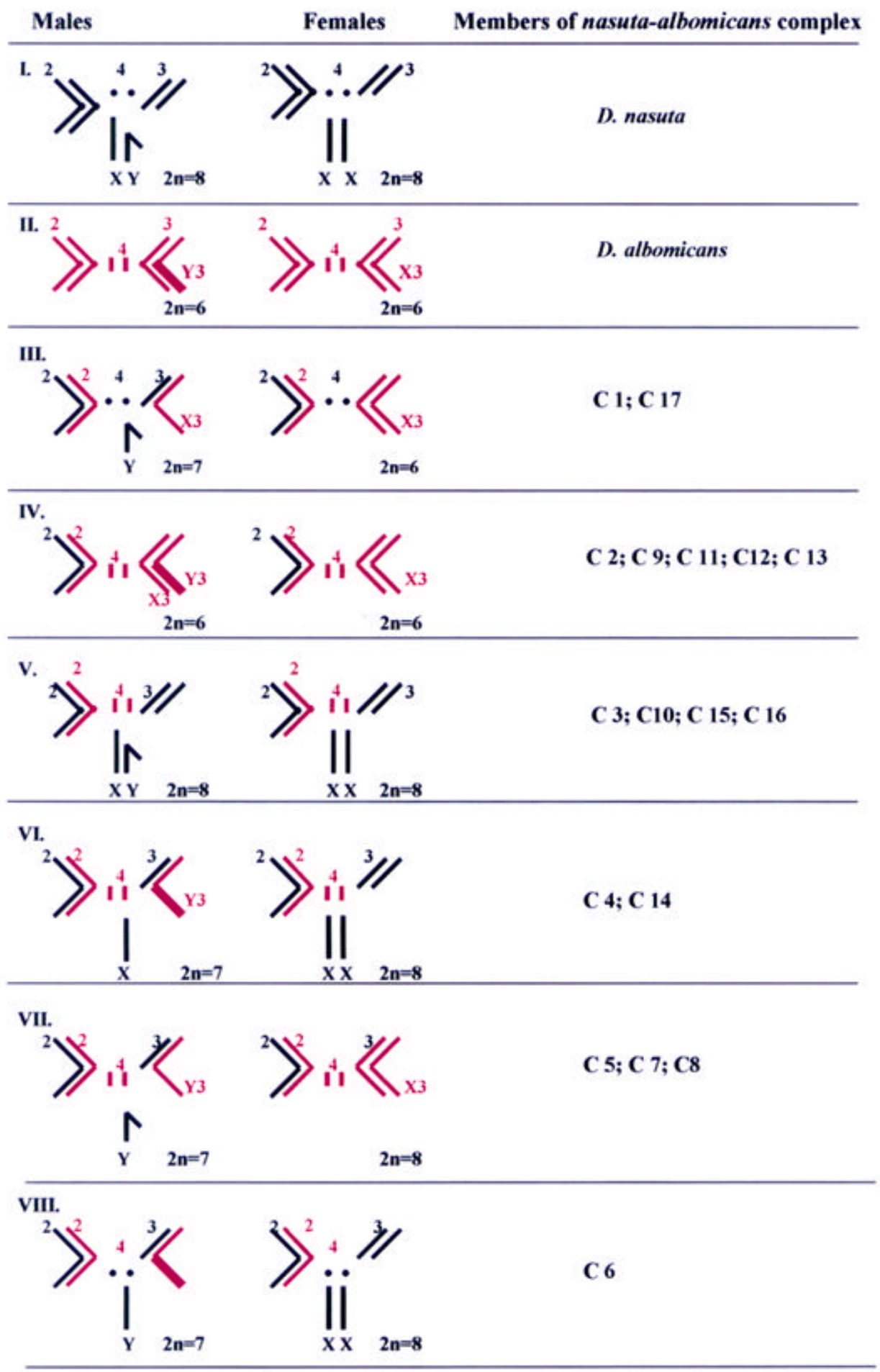

Figure 3. Interracial hybridization between $D$. nasuta and D. albomicans followed by maintenance of hybrid progeny for many generations has resulted in the emergence of populations with the introgressed stable karyotypes. Such populations with differential chromosomal representation of $D$. nasuta and $D$. albomicans are called cytoraces. This figure illustrates the karyotypic composition of the newly evolved assemblage called the 'nasuta-albomicans complex', which includes D. nasuta, D. albomicans and cytoraces. Note the different patterns of representation of the parental chromosomes in different cytoraces. 
fixed for the albomicans type of arrangement. On the other hand, among the males of the cytoraces all the four expected combinations are seen, albeit in different cytoraces. For these chromosomes, therefore, it appears that coassociation of parental elements was entertained in males only while stringent selection has been observed in females for homozygous association of nasuta or albomicans chromosomes. Thus there is a conflicting picture between male and female karyotypes of these cytoraces for the sex chromosomes and chromosome 3 .

A critical analysis of the trends in the karyotypic evolution of hybrid cytoraces suggests that interchange of the chromosomal material between corresponding homologous chromosomes of $D$. nasuta and D. albomicans is limited. Any genetic exchange between D. nasuta and D. albomicans chromosomes has to occur in heterozygotes. The $F_{1}$ heterozygote condition for the dot chromosomes is gradually replaced by homozygosity for one of the parental chromosomes. Even when these chromosomes coassociate in the hybrid, complete synapsis may not occur because of cytogenetic divergence between them. With regard to the sex chromosomes and autosome 3, females of cytoraces have either the D. nasuta complement $\left(3^{\mathrm{n}} 3^{\mathrm{n}} \mathrm{X}^{\mathrm{n}} \mathrm{X}^{\mathrm{n}}\right)$ or the D. albomicans complement $\left(\mathrm{X} \cdot 3^{\mathrm{a}} \mathrm{X} \cdot 3^{\mathrm{a}}\right)$. Thus, in the final stabilized karyotype, females are not heterozygous. Even when heterozygosity is present for these chromosomes $\left(\mathrm{X}^{\mathrm{n}} 3^{\mathrm{n}} \mathrm{X} \cdot 3^{\mathrm{a}}\right)$, for example in the $F_{1}$ and subsequent hybrid generations prior to karyotypic stabilization, the metacentric $\mathrm{X} \cdot 3^{\mathrm{a}}$ pairs with homologous acrocentric $3^{\mathrm{n}}$ and $\mathrm{X}^{\mathrm{n}}$ chromosomes. Even during this transient period, recombination between these elements might not have occurred freely, as also seen in the case of the genus Mus, where a crossover suppressor may operate in the vicinity of metacentric centromere (cf. Searle 1998). Thus it seems likely that only the second chromosomes of the parental species are together regularly in the hybrid genomes of the cytoraces, therefore limiting meiotic recombination to only this component of the hybrid genome.

An interesting facet reflected from the karyotypic studies on the hybrids of D. nasuta and D. albomicans is the lack of complete parental type of karyotype in any of the stabilized lines or cytoraces. Though there was preferential elimination or retention of specific chromosomes from either of the parents, D. albomicans chromosomes were more preferred than those of the D. nasuta parent. In so far stabilized 16 cytoraces, overall 221 chromosomes are present of which 98 chromosomes are of D. nasuta and 123 are of D. albomicans. Is it a reflection of cytoraces reverting to albomicans parental type?

\section{Stepwise evolution of a new race through centric fission}

Chromosomal fusion and fission are two basic mechanisms, apart from the ploidy, that result in alteration of the diploid chromosome number. White $(1973,1978)$ and King (1993) have discussed this at length to demonstrate the importance of chromosomal changes in the karyotype phylogeny of different animal and plant lineages. The evolution of the D. nasuta and D. albomicans karyotypes is known to have involved centric fusion (Ranganath and Hägele 1982). It has been postulated that the fusion of chromosomes and evolution of the new cytogenetic race D. albomicans occurred between 350,000 and 500,000 years ago (Chang and Ayala 1989; Chang et al. 1989). We now discuss whether such major changes in karyotypes can take place even in laboratory populations.

In one of the subpopulations of the hybrid lineage cytorace 1 , occurrence of a centric fission was recorded (Tanuja et al. 1999b). The metacentric chromosome $\mathrm{X} \cdot 3^{\mathrm{a}}$, which is considered to be derived from the fusion of $\mathrm{X}$ chromosome and chromosome 3 of a nasuta-like ancestor, had undergone fission to result in independent units, namely an X chromosome and chromosome 3 . This fission event was associated with the addition of heterochromatin in the form of a short arm to the $\mathrm{X}$ chromosome, making it submetacentric. The euchromatic arm of this submetacentric chromosome was homologous to the acrocentric X chromosome of D. nasuta. The other product of fission of $\mathrm{X} \cdot 3^{\mathrm{a}}$, the acrocentric chromosome 3 , was homologous to chromosome 3 of $D$. nasuta. Thus, this cytorace 1 population was dimorphic, with individuals with two types of chromosomal complements-the $\mathrm{X} \cdot 3^{\mathrm{a}}$ chromosome, or chromosomes 3 and X. From this population, males and females possessing only the products of centric fission were isolated and used to establish a new population, fission cytorace 1 (figure 4 ), with $2 n=8$ in both males and females (Tanuja et al. 1999b). This is yet another addition to the nasuta-albomicans complex of Drosophila. The uniqueness of fission cytorace 1 is not only that the products of fission are fixed in it, but also that it is the only member in this complex with a submetacentric $\mathrm{X}$ chromosome. The establishment of cytorace 1 took about 20 generations from the initial interracial hybridization between $D$. nasuta and D. albomicans. Subsequently, within a span of about 300 generations, we observed a major evolutionary change in karyotype giving rise to a new chromosomal lineage via centric fission. The observation of such karyotypic changes in regularly monitored laboratory systems is of great interest as it permits an empirical study of these cytogenetic processes important to raciation and speciation as they occur. This is an advance over the typical situation in which the past occurrence of such processes must be inferred from the karyotypes of extant species.

\section{The trap of an autosome in males of a cytorace}

One of the interesting aspects of study of the evolution of sex chromosomes is to account for heteromorphism 


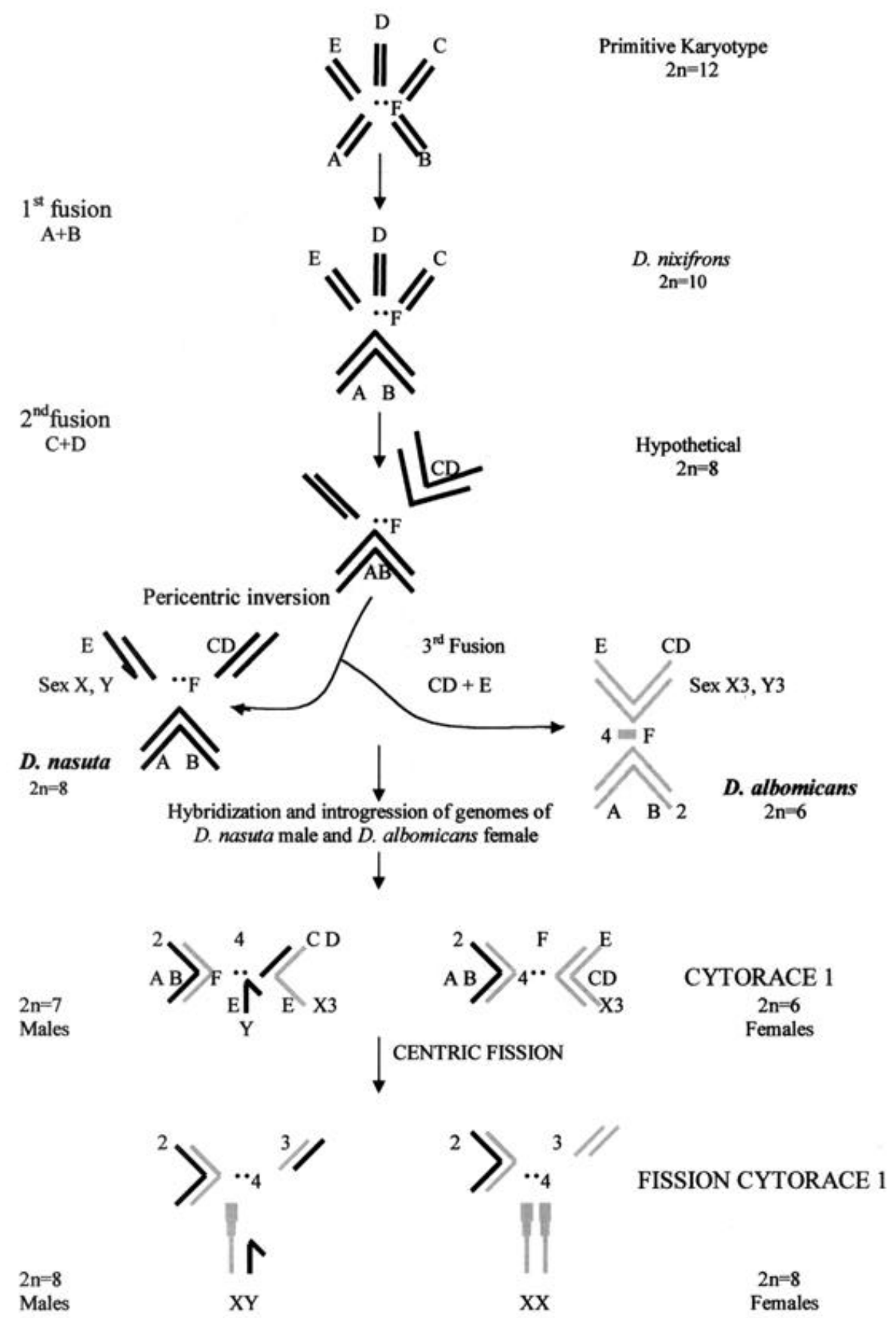

Figure 4. Karyotypic phylogeny of fission cytorace 1. The scheme is an extension of the karyotypic phylogeny of the nasuta subgroup given earlier by Ranganath and Hägele (1981). The primitive karyotypic constitution of Drosophila has $2 n=12$ (A to F). From this primitive setup Ranganath and Hägele (1981) have drawn the successive stages in the karyotypic evolution of the members of the nasuta subgroup. In this lineage, the karyotype of $D$. nasuta is a product of two centric fusions and a pericentric inversion. A third centric fusion has resulted in the evolution of the karyotype of $D$. $n$. albomicans. Cytorace I is the product of hybridization between males of D. nasuta and females of D. albomicans. Males and females of cytorace 1 have $2 n=7$ and $2 n=6$, respectively. The X3 chromosome has undergone centric fission to give rise to acrocentric chromosome 3 and a submetacentric X chromosome. Addition of heterochromatin after fission has occurred in this submetacentric $\mathrm{X}$ chromosome. These fission products are fixed in a subpopulation of cytorace 1 and this new lineage is referred to as fission cytorace 1 . 
(X and Y chromosomes) and associated dosage compensation. The density of active loci on the $\mathrm{Y}$ chromosome is usually very low, and the process leading to such inactivation of loci is called degeneration of $\mathrm{Y}$ chromosome. The dimorphic sex chromosomes $(\mathrm{X}, \mathrm{Y})$ are considered to have evolved from a pair of autosomes which slowly differentiated over millions of years (Muller 1918; Lucchesi 1978; Charlesworth 1996; Rice 1996a,b; Steinemann and Steinemann 1997; Marin et al. 2000).

Hybridization between D. nasuta and D. albomicans has given rise to introgressed cytoraces, where chromosomes of parents are represented in different combinations. One of the most notable events is that one of the autosomes of $D$. nasuta is restricted to only the male genome in cytorace 1. For instance, the acrocentric chromosome 3 , which is seen in both males and females of D. nasuta, is restricted to males of cytorace 1 . Therefore, in this cytorace, two chromosomes are limited to the male genome-the regular Y chromosome, and the acrocentric autosome 3 inherited from the D. nasuta parent (figure 5). As this autosome 3 is cosegregating with the $\mathrm{Y}$ chromosome and is limited to males, it is called a recent neo-Y chromosome (Tanuja et. al. 1999a). The polytene banding pattern of this neo-Y chromosome is completely homologous to the counterpart arm in $\mathrm{X} \cdot 3^{\mathrm{a}}$ chromosome of D. albomicans and to the chromosome $3^{\mathrm{n}}$ of D. nasuta, both of which are seen in females as well as males. The situation in cytorace 1 with reference to the $3^{\mathrm{n}}$ chromosome or the euchromatic arm $3^{\mathrm{a}}$ of the $\mathrm{X} \cdot 3^{\mathrm{a}}$ chromosome, and its homologue now found only in males, represents a classical case of sex chromosomes, wherein one of them is shuttling between males and females while the other remains in males only. As discussed by Muller (1918), Lucchesi (1978), Charlesworth (1996), Rice (1996a,b), Steinemann and Steinemann (1997) and Marin et al. (2000), the emergence of heteromorphic sex chromosomes from homomorphic predecessors can be due to many phenomena, such as the accumulation of deleterious mutations, absence of recombination in males, and accumulation of transposable elements. In nature, these phenomena are believed to occur over vast periods of time and it is difficult to study natural populations in the process of the emergence of heteromorphic sex chromosomes, leaving only the possibility of comparative studies of sex chromosomes of different ages. For example, studies have compared the structure of the Y chromosome of $D$. americana americana (a few hundred years old) and D. miranda (two million years old) in an attempt to illustrate the intermediate stages with different levels of degeneration in the evolution of dimorphic chromosomes (Charlesworth et al. 1997; Steinemann and Steinemann 1997). In this context, the case of the neo-sex chromosome of cytorace 1 is unique in that one of the autosomes of the parental race is inherited in a manner similar to that of a classical $\mathrm{Y}$ chromosome. The age of this neo-Y chromosome, which is euchromatic, is just about 600 generations, and it provides extremely good opportunities for future investigations on evolution of dimorphism in sex chromosomes.

\section{Isozymes}

Isozymes are among the molecular markers employed in evolutionary studies to assess the genetic variability within and genetic distance between races / species. Here we summarize results from a survey of isozyme variation in D. nasuta, D. albomicans, and four of the cytoraces, carried out to analyse the pattern of introgression in the hybrid genomes of the cytoraces. The introgressed populations are expected to exhibit alleles of both parents as well as new single-locus and multilocus genotypes. There have also been reports of novel alleles or 'hybrizymes' in hybrid zones of mammals, birds, reptiles, amphibians and insects (Woodruff 1989). In some studies, a moderate increase in allelic polymorphism in introgressed populations, compared to the parental taxa, has also been observed (Soltis 1985; De Pamphilis and Wyatt 1990). On the other hand, however, stabilized introgressants that are reproductively isolated from their parental taxa are often expected to have faced population bottlenecks, thus leading to decreased genetic variability relative to the progenitor populations (cf. Rieseberg and Wendel 1993).

The degree of introgression in the nasuta-albomicans complex was assessed among D. nasuta, D. albomicans and cytoraces 1-4, taking into consideration 11 isozymes: 1-esterase, 2-esterase, alkaline phosphatase, acid phosphatase, glucose-6-phosphate dehydrogenase, 1-glycerophosphate dehydrogenase, malate dehydrogenase, xanthine dehydrogenase, superoxide dismutase, octanol dehydrogenase and alcohol dehydrogenase (Aruna and Ranganath 2004). Overall, 122 alleles were identified, of which 52 alleles were common to all the six races analysed, nine were unique to one race, and 70 were common to at least two races. D. nasuta had 96 alleles, D. albomicans had 93, and cytorace 1 and cytorace 2 had 92 alleles, while cytorace 3 and cytorace 4 had 83 and 88 alleles, respectively. A comparison between the isozyme profiles of the parents, D. nasuta and D. albomicans, revealed that 16 alleles from $D$. nasuta are not found in D. albomicans and 13 alleles from $D$. albomicans are not found in D. nasuta. Thus these 29 alleles could, in principle, be used as diagnostic markers to trace the pattern of introgression in the stabilized hybrids. But, of the 16 alleles found in D. nasuta and not in D. albomicans, those for $2 \mathrm{Est}^{1.61}$ and G6PD ${ }^{1.20}$ were unique to D. nasuta, while of 13 alleles found in D. albomicans and not in D. nasuta, four were unique to $D$. $n$. albomicans, namely those for $2 \mathrm{Est}^{1.3}$, $\mathrm{Acph}^{1.05}, \mathrm{XDH}^{1.06}$ and $\alpha-\mathrm{GPD}^{0.91}$. Thus, only 23 alleles were finally employed to examine the introgression pattern of parental alleles among the cytoraces. Of the 16 alleles noticed in D. nasuta, 14 alleles were found to have 


\section{Primitive Karyotype}
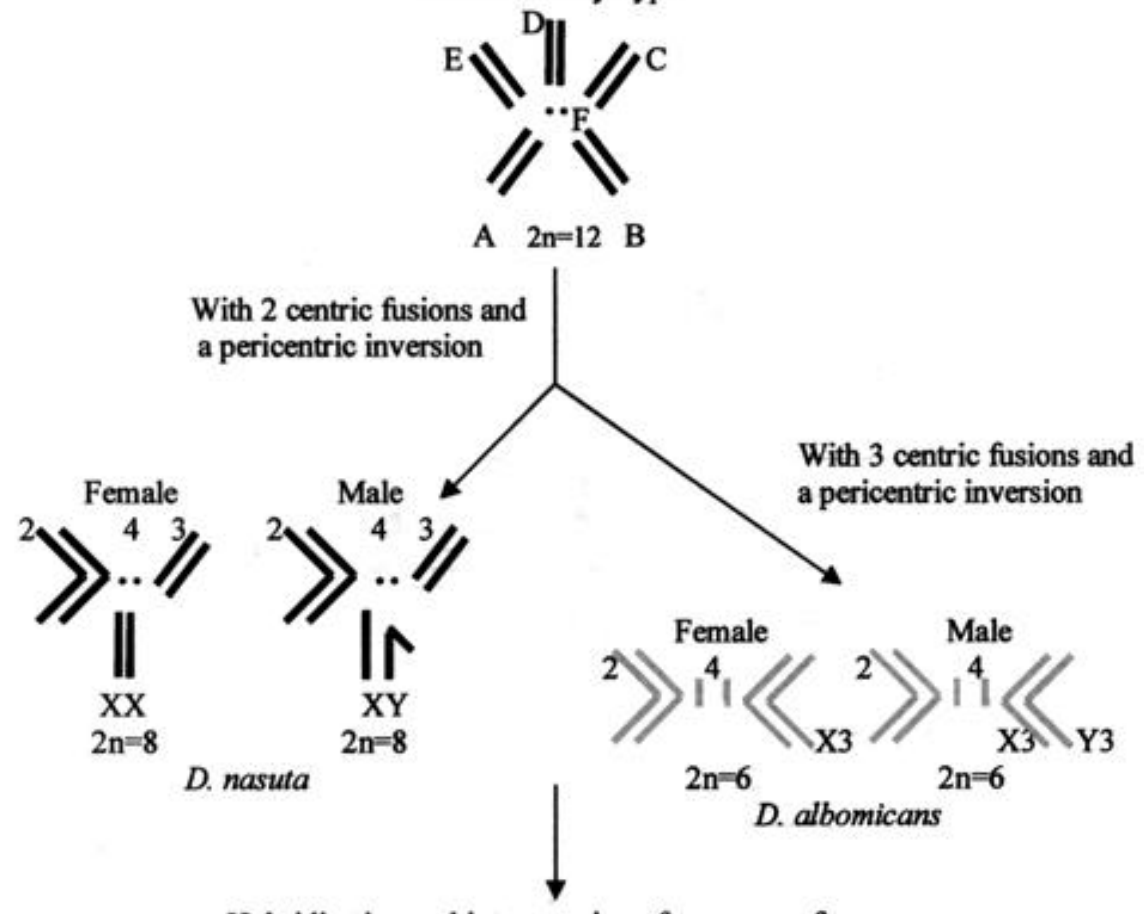

Hybridization and introgression of genomes of

D. nasuta male and $D$. albomicans female

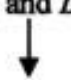

CYTORACE -1
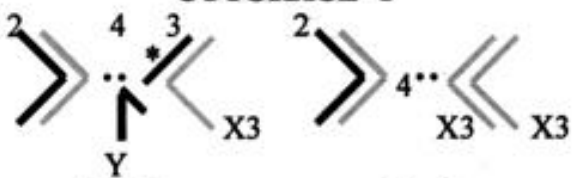

$2 n=7$

$2 n=6$

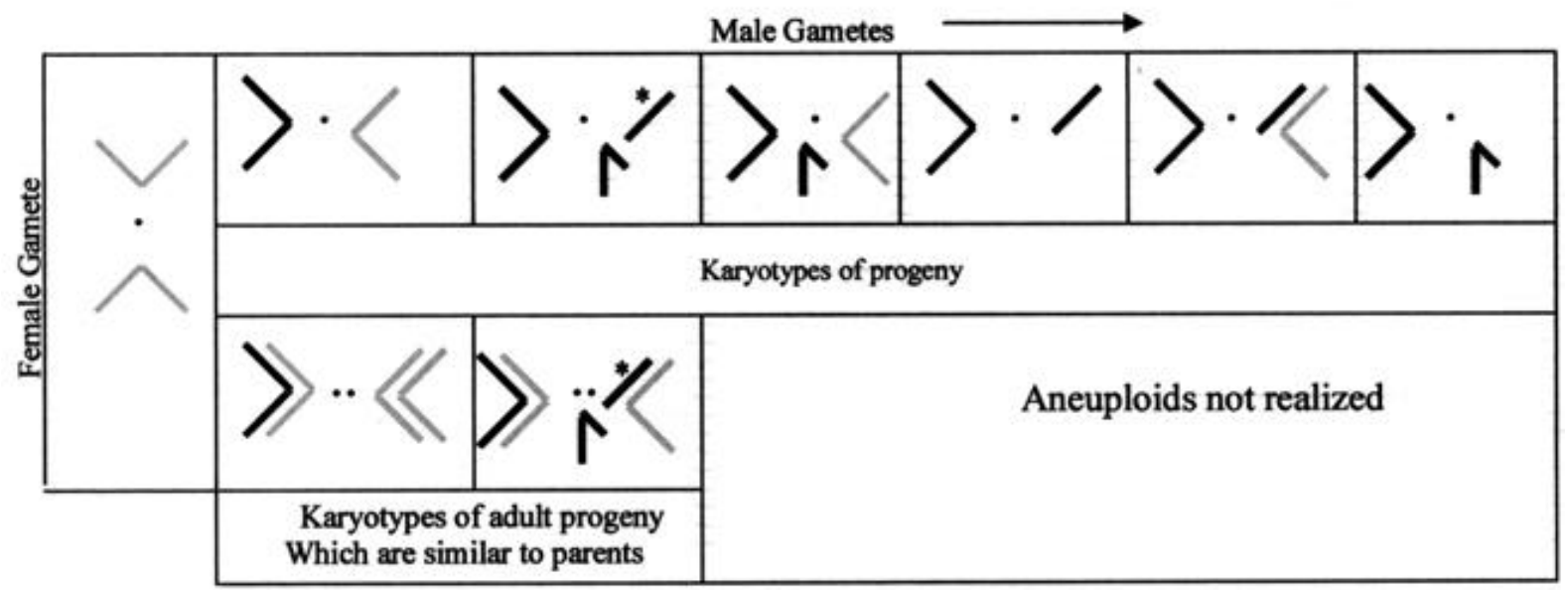

Figure 5. Chromosomal phylogeny of the neo-Y chromosome of cytorace 1 . Hybridization between males of D. nasuta and females of $D$. albomicans has led to the evolution of the karyotype of cytorace 1 which has $2 n=7$ in males and $2 n=6$ in females. Of the seven chromosomes of males, the acrocentric chromosome 3 , an autosome of the nasuta parent, is now restricted only to the male genome of cytorace 1 (chromosome with a $*$ ). The female produces only one type of gamete while males can produce six types of sperms, two with normal haploid quota of chromosomes and four that are aneuploids. But anueploid adults are not recorded. Therefore generation after generation males with $2 n=7$ and females with $2 n=6$ are produced and the acrocentric chromosome is found only in males. This chromosome is labelled as neo-Y chromosome. 
introgressed into the genomes of cytoraces with different frequencies. However, not all 14 alleles were common to all cytoraces; cytorace 1 had eight of the 14 alleles while cytorace 2, cytorace 3 and cytorace 4 had 10, eight and nine alleles, respectively. Of the nine alleles of $D$. albomicans, six were represented in cytorace 1 , and eight, five and six alleles were found to have introgressed into the genomes of cytorace 2 , cytorace 3 and cytorace 4 , respectively. If this comparison gave a measure of the extent of introgression of parental genomes, then the presence of novel alleles in the introgressed cytoraces revealed another aspect of hybridization. Thirteen alleles were found to be novel to the introgressed systems, the 'hybrizymes'. Of these, three alleles, namely those for $1 \mathrm{Est}^{0}, 2 \mathrm{Est}^{1.54}$ and $\mathrm{XDH}^{0.98}$, are unique to cytorace 4 (frequency $4.8 \%$ ), cytorace $2(3.7 \%)$ and cytorace $1(12.7 \%)$, respectively. Ten novel alleles were found in four cytoraces. The allele for $\mathrm{Aph}^{0.97}$ was noticed in all four cytoraces analysed, with an overall frequency of $26.6 \%$ for cytoraces. These hybrizymes may be recombined products of either the genes inherited from both the parents, or the products of genes obtained through recombination, or the reflection of gene expression in a coadapted hybrid genetic background.

Genetic distance estimates (Nei 1972) obtained from the frequency of the 122 alleles among the six races ranged from 0.091 to 0.219 , with the greatest distance between cytorace 1 and cytorace 3 , and the least distance between cytorace 1 and $D$. albomicans. Finally, the dendrogram based on genetic distance obtained by combined results of 11 isozymes using UPGMA (figure 6) indicates two clusters. In one clade, cytorace 1 and D. albomicans cluster with $D$. nasuta, whereas in the other clade cytorace 2 and cytorace 3 cluster with cytorace 4 . The parents,

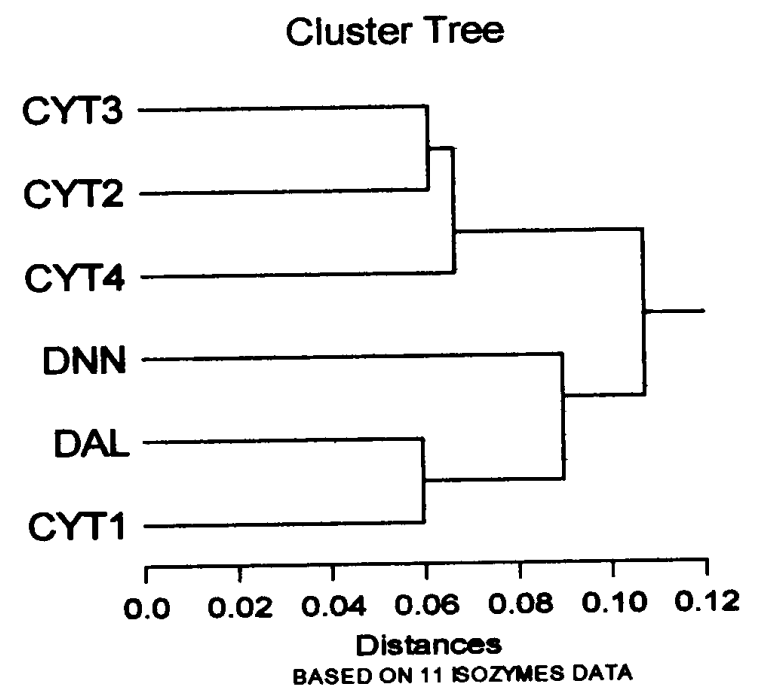

Figure 6. Dendrogram based on 11 isozymes for a few members of the nasuta-albomicans complex.
D. nasuta and D. albomicans, though separated about 500,000 years ago (Chang and Ayala 1989; Chang et al. 1989), still cluster together, while the cytoraces, which are only 350-500 generations old, form another cluster, underscoring the major role of hybridization in generating novel genetic variation.

\section{Incipient premating isolation}

In Drosophila sexual behaviour plays an important role in establishment of reproductive isolation between populations (Spieth 1968). Sexual behaviour includes a sequence of events of male courtship attempts and female responsive reaction, and even a slight deviation from the specific sexual behaviour can affect reproductive chances and fitness. However, in an introgressed system variations in reproductive behaviour are forced into the hybrids. Thus the occurrence of hybridization between races/species constitutes a challenge to which they have to respond either by developing or strengthening isolating mechanisms (Dobzhansky 1970), or by weakening isolation barriers, thereby making the interacting races/species more similar (Mayr 1963).

A detailed scrutiny of the mating behaviour among six races of the nasuta-albomicans complex showed the presence of 24 different courtship elements (M. C. Shilpa and H. A. Ranganath, unpublished data). Of these components of courtship, 15 were male specific, six were female specific, and three were due to both the sexes. The malespecific elements are anterior approach, posterior approach, transverse approach, tapping, anterior circle, posterior circle, left circle, right circle, full circle, wing extension, wing rippling, wing flicking, wing scissoring, wing waving, and attempt to copulate. The female-specific courtship elements are decamping, ignoring, kicking, wing fluttering, wing flicking and wing spreading. Courtship latency, courtship duration and copulation duration are due to both sexes involved. A study of these courtship elements revealed considerable divergence among the races studied (parental species and four cytoraces). Members of cytorace 1 and cytorace 4 possess all the 24 courtship elements, whereas D. nasuta, cytorace 2 and cytorace 3 have 23 elements, and D. albomicans has only 21 elements. Of the 24 courtship elements noticed, 20 were common to all the six races. Male anterior approach was not seen in males of cytorace 2 and cytorace 3, male wing waving was not seen in males of D. nasuta and D. albomicans, and female wing fluttering and female wing flicking were absent in females of D. albomicans. Thus, these cytogenetically closely related races of the nasutaalbomicans hybrid zone have shown symptoms of quantitative divergence for a few components of mating behaviour. The dendrogram based on these values is shown in figure 7 . 


\section{Incipient prezygotic isolation}

The widely accepted biological species concept emphasizes the importance of reproductive isolation to the process of speciation. Therefore any analysis of speciation or raciation analysis should include a systematic study of traits involved in prezygotic and postzygotic isolation. The extent of sexual isolation decides the status of relationship between populations. Populations that appear to be evolving either prezygotic or postzygotic reproductive isolation provide rare opportunities to follow the events in acquisition or emergence, or both, of characters that promote divergence between populations, facilitating reproductive isolation. Rather than looking at finished products of speciation to trace the evolutionary process involved in speciation, if one tries to unravel the events and processes of genetics of speciation in recently derived forms, then one gets an opportunity to understand and provide direct evidence for the mechanism and stages in the development of reproductive isolation. In this respect, the nasuta-albomicans hybrid zone, where variations in courtship elements have been recorded, provides an excellent model system for investigating the reproductive-isolation status of the members in the complex.

The performance of six races of the nasuta-albomicans complex during homogamic matings is summed up as follows: for mating latency cytorace $2>D$. nasuta $>$ cytorace $3>$ cytorace $4>$ cytorace $1>D$. albomicans, which gives a clear indication of interracial divergence. Similarly, in heterogamic matings under no-choice situation males of D. nasuta had the least mating latency and the longest copulation duration, while males of cytorace 2 showed exactly the opposite trend. On the other hand, females of $D$. albomicans showed minimum mating latency with prolonged period of copulation. The message

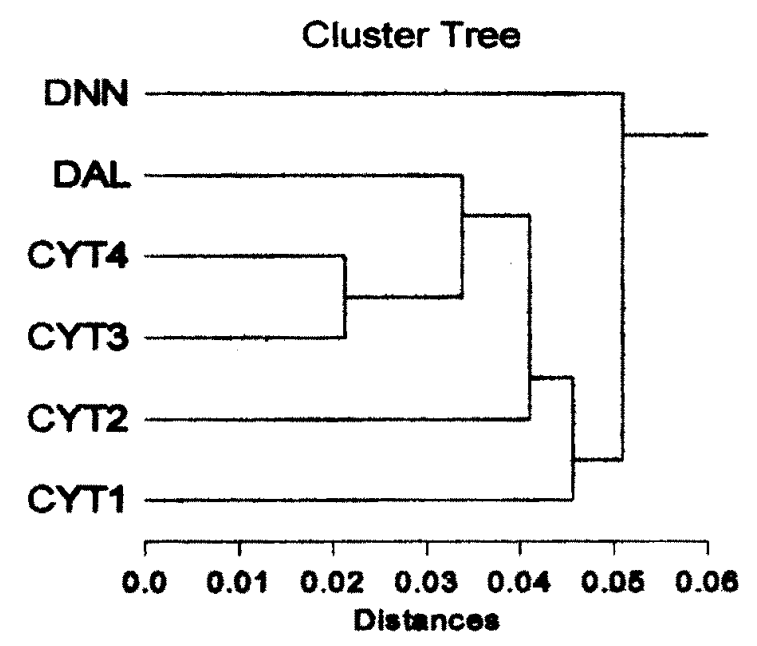

Figure 7. Dendrogram based on mating behaviour components for a few members of the nasuta-albomicans complex. from these experiments, described in detail by Tanuja et al. (2001a), is that these closely related races of the nasutaalbomicans complex show initiation of the earliest stages of prezygotic isolation, manifested as a tendency for matings to be initiated early and to last for a longer duration among homogamic rather than heterogamic matings. This is further substantiated in male-choice, female-choice and multiple-choice experiments. In these situations, the mating was far from random. Males of D. albomicans, cytorace 1 and cytorace 4 in male-choice experiments, females of cytorace 1 and cytorace 2 in female-choice experiments, and males and females of D. nasuta, D. albomicans, cytorace 1 and cytorace 4 against males and females of cytorace 2 in multiple-choice experiments had significantly more homogamic matings than expected (Tanuja et al. 2001b). Thus, by taking cognizance of divergence in the components of mating behaviour and the findings of mating-choice experiments, one can see the initiation of the earliest stages in the acquisition of reproductive isolation among the members of the nasuta-albomicans complex of Drosophila. We hope to continue to study the process of the development of reproductive isolation in this model system as it evolves further.

\section{Concluding remarks}

Stebbins (1973) has opined that mutation can never provide enough variability to allow major evolutionary advances to take place. Genetic recombination can be a major source of such variability, especially when accomplished by mass hybridization between populations with different adaptive norms. Templeton (1981) has argued that hybridization followed by production of unstable hybrids, inbreeding and hybrid breakdown may result in a form of natural selection favouring $\mathrm{F}_{2}$ and those later generations that have better viability and fertility. This may result in the formation of a new rare recombinant class of genotype. Experimental animal studies on hybridization do not usually extend beyond a few generations (Shaw and Wilkinson 1980; Scribner 1993; Price and Boake 1995). On the other hand, long-term effects should be considered for a better understanding of the evolutionary consequences of hybridization (Rieseberg and Carney 1998).

Interracial hybridization between D. nasuta and D. albomicans, and maintenance of hybrid populations for over 600 generations, have resulted in an excellent model system providing evidence to substantiate many hypotheses laid out by Stebbins (1973), Templeton (1981) and Rieseberg and Carney (1998). Introgression of genomes of D. nasuta and D. albomicans and transgressive segregation of parental features in different patterns in different lineages have given rise to different genetic systems called cytoraces. These cytoraces are passing through the 
process of anagenesis and reflect different stages of population differentiation. The nasuta-albomicans complex, a cluster of allo-sympatric populations, constituting an artificial hybrid zone in the environs of the laboratory, provides a tractable system for large-scale evolutionary experimentation on raciation and speciation.

\section{Acknowledgements}

H A Ranganath acknowledges the collaborative help received from N. B. Krishnamurthy, K. Hägele, N. B. Ramachandra, M. T. Tanuja and M. C. Shilpa during these investigations, and also the financial assistance received from different funding agencies, namely UGC, CSIR, DBT and DST of the Government of India, and DAAD (Germany) at different points of time.

\section{References}

Anderson E. 1949 Introgressive hybridization. Wiley, New York. Anderson W. W. and Stebbins G. L. 1954 Hybridization as an evolutionary stimulus. Evolution 8, 378-388.

Arnold M. L. 1997 Natural hybridization and evolution. Oxford University Press. New York.

Aruna S and Ranganath H. A. 2004 Isozymes and genetic divergence in the nasuta-albomicans complex of Drosophila. Curr. Sci. (in press).

Avise J. C. 1994 Molecular markers, natural history and evolution. Chapman and Hall, New York.

Barton N. H. 2001 The role of hybridization in evolution. Mol. Ecol. 10, 551-568.

Barton N. H. and Hewitt G. M. 1989 Adaptation, speciation and hybrid zones. Nature 341, 497-503.

Bock I. R. 1984 Interspecific hybridization in the genus Drosophila. Evol. Biol. 18, 41-70.

Bruke J. M and Arnold M. L. 2001 Genetics and the fitness of hybrids. Annu. Rev. Genet. 35, 31-52.

Carson H. L. 1982 Evolution of Drosophila on the newer Hawaiian volcanoes. Heredity 48, 3-25.

Chang H. and Ayala F. J. 1989 On the origin of incipient reproductive isolation: the case of Drosophila albomicans and Drosophila nasuta. Evolution 43, 1614-1624.

Chang H., Wang D. and Ayala F. J. 1989 Mitochondrial DNA evolution in the Drosophila nasuta subgroup of species. J. Mol. Evol. 28, 337-348.

Charlesworth B. 1996 The evolution of chromosomal sex determination and dosage compensation. Curr. Biol. 6, 149162.

Charlesworth B., Charlesworth D., Hnilicka J., Yu A. and Guttman D. S. 1997 Lack of degeneration of loci on the neo-Y chromosome of Drosophila americana americana. Genetics 145, 989-1002.

Cracraft J. 1983 Species concepts and speciation analyses. Curr. Ornithol. 1, 159-187.

Cruzan M. B. and Arnold M. L. 1993 Ecological and genetic associations in an Iris hybrid zone. Evolution 47, 1432-1445.

De Pamphilis C. W. and Wyatt R. 1990 Electrophoretic confirmation of interspecific hybridization in Aesculus (Hippocastanaceae) and the genetic structure of a broad hybrid zone. Evolution 44, 1295-1317.

Dobzansky Th. 1949 Observations and experiments on natural populations in Drosophila. (Proceedings of the 8th Interna- tional Congress of Genetics 1948) Hereditas (suppl. vol.) 210-224.

Dobzhansky Th. 1970a Speciation as a stage in evolutionary divergence. Am. Nat. 74, 312-321.

Dobzhansky Th. 1970b The genetics of the evolutionary process. Columbia University Press, New York.

Fritz R. S. 1999 Hybridization and resistance to parasites. Ecology 80, 359-360.

Goodman S. J., Barton N. H., Swanson G., Abernethy K. and Pemberton J. M. 1999 Introgression through rare hybridization: a genetic study of a hybrid zone between red and sika deer (Genus: Cervus), in Argyll, Scotland. Genetics 152, $355-371$.

Hägele K. and Ranganath H. A. 1982 The chromosomes of two Drosophila races: D. nasuta nasuta and D. nasuta albomicana. II. Differences in their microchromosomes. Chromosoma $\mathbf{8 5}, 215-220$.

Hägele K. and Ranganath H. A. 1983 The chromosomes of two Drosophila races: D. nasuta nasuta and D. nasuta albomicana. III. Localization of nucleolar organizer regions. Genetica 60, 123-128.

Haldane J. B. S. 1922 Sex-ratio and unisexual sterility in hybrid animals. J. Genet. 12, 101-109.

Harrison R. S. 1990 Hybrid zones: windows on evolutionary process. Oxf. Surv. Evol. Biol. 7, 158-167.

Hewitt G. M. 1988 Hybrid zones-natural laboratories for evolutionary studies. Trends Ecol. Evol. 3, 158-167.

King M. 1993 Species evolution: the role of chromosome change. Cambridge University Press, Cambridge.

Kitagawa O., Wakahama K., Fuyama Y., Shimada Y., Takanashi E., Hatsumi M., Uwabo M. and Mita Y. 1982 Genetic studies of the Drosophila nasuta subgroup, with notes on distribution and morphology. Jpn. J. Genet. 57, $113-141$

Lucchesi J. C. 1978 Gene dosage compensation and the evolution of sex chromosomes. Science 202, 711-716.

McAllister B. F. 2002 Chromosomal and allelic variation in Drosophila americana: selective maintenance of a chromosomal cline. Genome 45, 13-21.

Mahesh G., Ramachandra N. B. and Ranganath H. A. 2000 Patterns of replication in the neo-sex chromosomes of Drosophila nasuta albomicans. J. Biosci. 25, 229-234.

Mahesh G., Ramachandra N. B. and Ranganath H. A. 2001 Autoradiographic study of transcription and dosage compensation in the sex and neo-sex chromosomes of D. n. nasuta and D. n. albomicans. Genome 44, 71-78.

Marin I., Siegal M. L. and Baker B. S. 2000 The evolution of dosage-compensation mechanisms. BioEssays 22, 11061114.

Mayr E. 1963 Animal species and evolution. Belknap Press of Harvard University, Cambridge.

Muller H. J. 1918 Genetic variability, twin hybrids and constant hybrids in a case of balanced lethal factors. Genetics 93, 422-499.

Nei M. 1972 Genetic distance between populations. Am. Nat. 106, 283-292.

Nirmala S. S. and Krishnamurthy N. B. 1972 Drosophila albomicans-a race of Drosophila nasuta. Drosoph. Inf. Serv. 49, 60.

Patterson J. T. and Stone W. S. 1952 Evolution in the genus Drosophila. Macmillan, New York.

Price D. K. and Boake C. R. B. 1995 Behavioral reproductive isolation in Drosophila silvestris, D. heteroneura, and their $\mathrm{F}_{1}$ hybrids (Diptera, Drosophilidae). J. Insect Behav. 8, 595616.

Rajasekarasetty M. R., Siddaveere Gowda L., Krishnamurthy 


\section{H. A. Ranganath and S. Aruna}

N. B. and Ranganath H. A. 1979 Population genetics of Drosophila nasuta nasuta, Drosophila nasuta albomicana and their hybrids. I. Karyotypic mosaicism in hybrid populations, Genetics 93, 211-215.

Ramachandra N. B. and Ranganath H. A. 1985 The chromosomes of two races: Drosophila nasuta nasuta and Drosophila nasuta albomicana: IV. Hybridization karyotype repatterning. Chromosoma 93, 243-248.

Ramachandra N. B. and Ranganath H. A. 1987 Mating preference between Drosophila nasuta nasuta and D. nasuta albomicana. Indian J. Exp. Biol. 25, 55-57.

Ramachandra N. B. and Ranganath H. A. 1988 Estimation of population fitness of parental races (Drosophila nasuta nasuta, Drosophila nasuta albomicana) and of the newly evolved Cytoraces (I and II) - the products of parental interracial hybridization. Genome 30, 58-62.

Ramachandra N. B. and Ranganath H. A. 1990 The chromosomes of two Drosophila races: Drosophila nasuta nasuta and Drosophila nasuta albomicana: V. Introgression and the evolution of new karyotypes. Z. Zool. Syst. Evolutionsforsch. 28, 62-68.

Ramachandra N. B. and Ranganath H. A. 1996 Evolution of the nasuta-albomicans complex of Drosophila. Curr. Sci. 71, 515517.

Ranganath H. A. 1978 Population genetics of Drosophila nasuta nasuta and Drosophila nasuta albomicana and their hybrids (Science Academy Medals for Young Scientists Lectures). Proc. Indian Natl. Sci. Acad. 124-139.

Ranganath H. A. 2002 Evolutionary biology of Drosophila nasuta and Drosophila albomicans. Proc. Indian Natl. Sci. Acad. B68, 255-272.

Ranganath H. A. and Hägele K. 1981 Karyotypic orthoselection in Drosophila. Naturwisssenschaften 68, 527-528.

Ranganath H. A. and Hägele K. 1982 The chromosomes of two Drosophila races: D. nasuta nasuta and D. nasuta albomicans. I. Distribution and differentiation of heterochromatin. Chromosoma 85, 83-92.

Ranganath H. A. and Krishnamurthy N. B. 1981 Population genetics of Drosophila nasuta nasuta, D. nasuta albomicana and their hybrids. IV. Pattern of meiotic $F_{1}$ chromosome segregation. J. Hered. 72, 19-21.

Ranganath H. A. and Ramachandra N. B. 1987 Chromosomal basis of raciation in Drosophila: A study with Drosophila nasuta and Drosophila albomicans. Proc. Indian Acad. Sci. (Anim. Sci.) 96, 451-459.

Ranganath H. A. and Ramachandra N. B. 1994 Drosophila albomicans - a unique karyotype. The Nucleus 37, 105-112.

Ranganath H. A., Rajasekarasetty M. R. and Krishnamurthy N. B. 1974 Evolutionary status of Indian Drosophila nasuta. Indian J. Hered. 6, 19-25.

Ranganath H. A., Schmidt E. R. and Hägele K. 1982 Satellite DNA of Drosophila nasuta nasuta and D. nasuta albomicana: localization in polytene and metaphase chromosomes. Chromosoma 85, 361-368.

Rao P. and Ranganath H. A. 1990 Karyotype differentiation among members of the immigrans species group of Drosophila. Genetica $\mathbf{8 3}, 145-152$.

Rice W. R. 1996a Degeneration of a non-recombining chromosome. Science 263, 230-232.

Rice W. R. 1996b Evolution of the Y sex chromosome in animals: Y-chromosomes evolve through the degeneration of autosomes. Bioscience 46, 331-343.

Rieseberg L. H. and Carney S. E. 1998 Transley review no. 102. Plant hybridization. New Phytol. 140, 599-624.

Rieseberg L. H. and Wendel J. F. 1993 Introgression and its consequences in plants. In Hybrid zones and the evolutionary process (ed. R. G. Harrison), pp. 70-113. Oxford University Press, New York.

Rieseberg L. H., Sinverno B., Linder C. R., Ungerer M. C. and Arrias D. M. 1996 Role of gene interactions in hybrid speciation: evidences from ancient and experimental hybrids. Science 272, 741-745.

Rieseberg L. H., Archer M. A. and Wayne R. K. 1999 Transgressive segregation, adaptation and speciation. Heredity $\mathbf{8 3}$, 363-372.

Scribner K. T. 1993 Hybrid zone dynamics are influenced by genotype-specific variation in life-history traits: experimental evidence from hybridizing Gambusa species. Evolution 47, 632-646.

Searle J. B. 1998 Speciation, chromosomes and genomes. Genome Res. 8, 1-3.

Shaw D. D. and Wilkinson P. 1980 Chromosome differentiation, hybrid breakdown and the maintenance of a narrow hybrid zone in Caledia. Chromosoma $\mathbf{8 0}, 1-31$.

Soltis P. 1985 Studies of genetic variation in an introgressive complex in Clarkia (Oragyaceae). Ph. D. thesis, University of Kansas, Lawrence, USA.

Spieth H. T. 1968 Evolutionary implications of sexual behaviour in Drosophila. In Evolutionary biology (ed. Th. Dobzhansky, M. K. Hecht and W. C. Streere), vol. 2, pp. 157-191. Appleton Century Crofts, New York.

Stebbins G. L. 1973 Process of organic evolution. PrenticeHall of India, New Delhi.

Steinemann M. and Steinemann S. 1997 The enigma of Y chromosome: TRAM, a novel retrotransposon is preferentially located on the Neo-Y chromosome of Drosophila miranda. Genetics 145, 261-266.

Tanuja M. T. 2000 Studies on karyotype, fitness and mating preference of a few members of the nasuta-albomicans complex of Drosophila. Ph. D. thesis, University of Mysore, Mysore, India.

Tanuja M. T., Ramachandra N. B. and Ranganath H. A. 1998 Creation of a hybrid zone in Drosophila with 'allo-sympatric' races. Curr. Sci. 75, 1116-1117.

Tanuja M. T., Ramachandra N. B. and Ranganath H. A. 1999a Evolution of a recent neo-Y sex chromosome in a laboratory population of Drosophila. J. Genet. 78, 81-85.

Tanuja M. T., Ramachandra N. B. and Ranganath H. A. 1999b Evolution of a new chromosomal lineage in a laboratory population of Drosophila through centric fission. J. Biosci. 24, 421-426.

Tanuja M. T., Ramachandra N. B. and Ranganath H. A. 2001a Incipient sexual isolation in the nasuta-albomicans complex of Drosophila: no-choice experiments. J. Biosci. 26, 71-76.

Tanuja M. T., Ramachandra N. B. and Ranganath H. A. 2001b Incipient sexual isolation in the nasuta-albomicans complex of Drosophila: mating preference in male-, female-, and multiple-choice mating experiments. J. Biosci. 26, 365-371.

Tanuja M. T., Ramachandra N. B. and Ranganath H. A. 2003 Hybridization and introgression of the genomes of Drosophila nasuta and Drosophila albomicans: evolution of new karyotypes. Genome 46, 605-611.

Templeton A. R. 1981 Mechanisms of speciation-a population genetic approach. Annu. Rev. Ecol. Syst. 12, 23-48.

Throckmorton L. H. 1982 The virilis species group. In The genetics and biology of Drosophila (ed. M. Ashburner, H. L. Carson and J. N. Thompson Jr), vol. 3b, pp. 227-296. Academic Press, London.

Wasserman M. 1982 Evolution in the repleta group. In The genetics and biology of Drosophila (ed. M. Ashburner, H. L. Carson and J. N. Thompson Jr), vol. 3b, pp. 61-139. Academic Press, London. 
White M. J. D. 1973 Animal cytology and evolution, 3rd edition. Cambridge University Press, Cambridge.

White M. J. D. 1978 Modes of speciation. Freeman, San Francisco.

Wilson F. D., Wheeler M. R., Margaret H. and Kambysellis M. 1969 Cytogenetics relations in the Drosophila nasuta subgroup of the immigrans group of species. Univ. Tex. Publ. 6918, 207-254.
Woodruff D. S. 1989 Genetic anomalies associated with Cerion hybrid zones: the origin and maintenance of the new electromorphic variants called hybrizymes. Biol. J. Linn. Soc. 36, 281-294.

Yu Y., Lin F. and Chang H. 1997 Karyotype polymorphism in hybrid populations of Drosophila nasuta and Drosophila albomicans. Zool. Studies 36, 251-259. 